\title{
The prognostic impact of Akt isoforms, PI3K and PTEN related to female steroid hormone receptors in soft tissue sarcomas
}

\author{
Andrej Valkov ${ }^{1,2^{*}}$, Thomas K Kilvaer ${ }^{2}$, Sveinung W Sorbye ${ }^{1,2}$, Tom Donnem ${ }^{3,4}$, Eivind Smeland ${ }^{3}$, Roy M Bremnes ${ }^{3,4}$ \\ and Lill-Tove Busund ${ }^{1,2}$
}

\begin{abstract}
Background: The PI3K/Akt pathway is involved in cellular survival pathways by inhibiting apoptotic processes and stimulating cell growth and proliferation. Its negative prognostic value has been proven in many types of cancer. In soft tissue sarcomas, the expression profiles of the PI3K/Akt pathway components are poorly defined and their significance uncertain. We aimed to investigate the prognostic impact of Akt (Akt1) phosphorylated at threonine $e^{308}$ and serine ${ }^{473}, \mathrm{Akt} 2, \mathrm{Akt3}, \mathrm{PI3K}$ and PTEN, alone and in coexpression with ER and PgR in non-gastrointestinal stromal tumor soft tissue sarcomas (non-GIST STSs).
\end{abstract}

Patients and methods: Tumor samples and clinical data from 249 patients with non-GIST STS were obtained, and tissue microarrays (TMAs) were constructed. Immunohistochemistry (IHC) was used to evaluate marker expression in tumor cells.

Results: In univariate analyses, the expression levels of $p-A k t ~ T h r^{308}(P=0.002)$, Akt2 $(P=0.008)$ and $P I 3 K(P<$ 0.001 ) were significant prognostic factors. In the multivariate analysis, high PI3K expression was an independent negative prognosticator $(\mathrm{HR}=1.5,95 \% \mathrm{Cl}=1.0-2.2, \mathrm{P}=0.042)$ in addition to advanced age, tumor depth, high malignancy grade, metastasis at diagnosis, surgery and positive resection margins. p-Akt Thr ${ }^{308}$ expression had strong unfavorable effect in men only $(P=0.009)$. In contrast, $\mathrm{p}$-Akt $\mathrm{Ser}^{473}$ expression had strong unfavorable impact in women $(P=0.023)$. PgR-/p-Akt Ser ${ }^{473}+$ phenotype tended to have less favorable impact in women $(P=$ 0.087), but was the most favorable one in men $(P=0.010)$.

Conclusion: Expression of PI3K was significantly associated with aggressive behavior and shorter DSS in non-GIST STS. The site of Akt phosphorylation seems to have gender-dependent impact on survival in STS patients.

Keywords: soft tissue sarcomas, Akt isoforms, PI3K, PTEN, ER, PgR, disease-specific survival

\section{Background}

Soft tissue sarcomas (STS) are malignant tumors arising from extraskeletal connective tissues. They are heterogeneous neoplasms, consisting of more than 50 subtypes, and comprise less than $1 \%$ of adult malignancies [1,2]. Approximately $50 \%$ of the STS patients will succumb to their disease because of metastasis or local progression [3]. The prognostic factors determining tumor evolution and ultimately patients' fate include tumor grade, size,

\footnotetext{
* Correspondence: Andrej.Yurjevic.Valkov@unn.no

'Dept of Clinical Pathology, University Hospital of Northern Norway, Tromsø, Norway

Full list of author information is available at the end of the article
}

location, depth, histological entity, positive resection margins and presence of local relapse [4-10]. In addition, an array of recurrent gene aberrations are found to be prognostic and predictive biomarkers in STSs [11-13].

Akt is a serine/threonine protein kinase that exists in three possible isoforms, including Akt1, Akt2, and Akt3. Akt can be activated by phosphorylation at threonine ${ }^{308}$ or at serine ${ }^{473}$ for Akt1 or homologous sites for Akt2 and Akt3 by phosphatases which along with Akt isoforms, belong to the phosphoinositide 3-kinase (PI3K)/ Akt pathway. The PI3K/Akt pathway has been linked to an extraordinarily diverse group of cellular functions,

\section{() Biomed Central}


including cell growth, proliferation, differentiation, motility, survival, intracellular trafficking and angiogenesis [14]. Both PI3K and Akt isoforms have been implicated as major players in many types of cancer [15-17].

The PI3K/Akt pathway seems to be more often deregulated in cancer than any other pathway [18]. However, in the literature there is disagreement regarding the prognostic impact of Akt expression. While the majority of studies agree that Akt expression overtly indicates a poor prognosis [19-21], there are several studies showing the opposite effect [22,23]. Expressions of PI3K/Akt pathway components have rarely been investigated in STSs and there are almost no studies devoted to their prognostic value [24].

Different physiological function of the Akt family kinases implies that the expression of its isoforms may also have different prognostic impact in cancer. The significance of this variation for the survival of the STS patients is not well investigated and it is not clear whether the site of phosphorylation and the pattern of expression can play prognostic roles.

In previous studies, we have shown the prognostic value of female steroid hormone receptors in STSs, both alone and in the coexpression with TGF- $\beta$ and fascin $[25,26]$. Such prognostic impact is not surprising, since both ER and PgR regulate growth and cell differentiation upon ligand-dependent and ligand-independent activation and are in essence growth factors. In this context we wanted to explore the correlations between female hormone receptors and the members of PI3K/Akt signaling pathway. To our knowledge, these correlations have not been described previously.

In this study, we investigate the prognostic impact of all isoforms of Akt (phosphorylated at threonine ${ }^{308}$ and Akt phosphorylated at serine ${ }^{473}$, non-phosphorylated Akt2, and total Akt3), PI3K, PTEN, ER and PgR in 249 non-GIST STS patients. GIST cases were excluded from the study since patients with this subtype of sarcoma receive a specific treatment regimen which resulted in significantly better survival.

\section{Materials and methods}

\section{Patients and clinical samples}

Primary tumor tissue from anonymized patients diagnosed with non-GIST STS at the University Hospital of North Norway (UNN) 1973-2006 and The Hospitals of Arkhangelsk region, Russia, were used in this retrospective study. In total, 496 patients were registered from the hospital databases. Of these, 247 patients were excluded due to missing clinical data $(n=86)$ or inadequate material for histological examination $(\mathrm{n}=$ 161). Thus, 249 STS patients with full clinical records and adequate paraffin-embedded tissue blocks were eligible.
This report includes follow-up data as of September 2009. The median follow-up was 38 (range 0.1 - 392) months. Formalin-fixed and paraffin-embedded tumor specimens were obtained from the archives of the Departments of Pathology at UNN and the Arkhangelsk hospitals. The tumors were graded according to the French Fèdèration Nationales des Centres de Lutte Contre le Cancer (FNCLCC)[27].

\section{Microarray construction}

All sarcomas were histologically reviewed by two trained pathologists (S.S. and A.V.) and the most representative areas of viable tumor cells (neoplastic cells) were carefully selected and marked on the hematoxylin and eosin (H\&E)-stained slides and sampled for the tissue microarray blocks (TMAs). The TMAs were assembled using a tissue-arraying instrument (Beecher Instruments, Silver Springs, MD). The Detailed methodology has been previously reported [28]. Briefly, we used a $0.6 \mathrm{~mm}$ diameter stylet, and the study specimens were routinely sampled with two replicate core samples (different areas) of neoplastic tissue. To include all core samples, 12 tissue array blocks were constructed. Multiple 4- $\mu \mathrm{m}$ sections were cut with a Micron microtome (HM355S) and stained using specific antibodies for immunohistochemistry (IHC) analyses.

\section{Immunohistochemistry (IHC)}

The applied antibodies were subjected to in-house validation by the manufacturer for IHC analysis on paraffin-embedded material. The applied antibodies had been subjected to in-house validation by the manufacturer for IHC analysis on paraffin-embedded material. The antibodies used in the study were as follows: Phospho-Akt (Ser473) (1:5; Rabbit monoclonal, clone 736E11; \#3787; Cell Signalling Technology, Danvers, U.S.A.), detects Akt 1 only when phosphorylated at serine 473, and Akt2 and Akt3 only when phosphorylated at equivalent sites. Phospho-Akt (Thr308) (1:50; Rabbit monoclonal, clone 244F9; \#4056; Cell Signalling Technology), recognizes all three Akt isoforms when phosphorylated at this site. Akt2 (1:18; Rabbit monoclonal, clone 54G8; \#4057; Cell Signalling Technology), preferentially binds to nonphosphorylated endogenous levels of Akt2. It does not cross-react with recombinant Akt1 or Akt3. Akt3 (1:8; Rabbit polyclonal, \#4059; Cell Signalling Technology), detects endogenous levels of total Akt3, but does not recognize the truncated form of rat Akt3. The antibody does not cross-react with recombinant Akt1 or Akt2. PTEN (1:10, Rabbit monoclonal; \#9559; Cell Signalling Technology), detects endogenous levels of total PTEN protein. PI3K (1:25; Rabbit polyclonal; \#4254; Cell Signalling Technology), detects endogenous levels of total PI3K. 
Sections were deparaffinised with xylene and rehydrated with ethanol. Antigen retrieval was performed by placing the specimen in $0.01 \mathrm{~mol} / \mathrm{l}$ citrate buffer at $\mathrm{pH}$ 6.0 and exposed to two repeated microwave heatings of 10 minutes at $450 \mathrm{~W}$. The DAKO EnVision + SystemHRP (DAB) kit was used as endogen peroxidase blocking. Primary antibodies were incubated overnight at $4{ }^{\circ} \mathrm{C}$ (except PI3K, for 32 minutes at room temperature). The DAKO EnVision+ System-HRP (DAB) kit was used to visualize the antigens for all stains. This yielded a brown reaction product at the site of the target antigen. As negative staining controls, the primary antibodies were replaced with the primary antibody diluent. Finally, all slides were counterstained with hematoxylin to visualize the nuclei. For each antibody, including negative controls, all TMA staining were performed in one single experiment. The immunohistochemical staining for ER and PgR was performed as described earlier[25].

\section{Scoring of IHC}

The ARIOL imaging system (Genetix, San Jose, CA) was used to scan the slides with immunohistochemically stained TMAs. The specimens were scanned at a low resolution $(1.25 \times)$ and high resolution $(20 \times)$ using Olympus BX 61 microscope with an automated platform (Prior). The slides were loaded in the automated slide loader (Applied Imaging SL 50). Representative and viable tissue sections were scored manually on computer screen, semiquantitatively for cytoplasmic staining for PI3K/Akt pathway components and for nuclear staining for ER and PgR. The dominant staining intensity in neoplastic cells was scored subjectively as: $0=$ negative; $1=$ weak; 2 = intermediate; 3 = strong (Figure 1 ). For ER and PgR, the modified All Red scoring system [25] was used. All samples were anonymized and independently scored by two pathologists (A.V. and S.S.). In cases where score difference was equal to or exceeding 2 , the slides were re-examined and a consensus was reached by the observers. When assessing a score for a given core, the observers were blinded to the scores of the other variables and to outcome. Mean score for duplicate cores from each individual was calculated.

\section{Statistical methods}

All statistical analyses were done using the statistical package SPSS (Chicago, IL), version 16. The IHC scores from each observer were compared for interobserver reliability by use of a two-way random effect model with absolute agreement definition. The intraclass correlation coefficient (reliability coefficient) was obtained from these results. The Chi-square test and Fishers Exact test were used to examine the association between molecular marker expression and various clinicopathological parameters. Univariate analyses were done by using the
Kaplan-Meier method, and statistical significance between survival curves was assessed by the log rank test. Disease-specific survival (DSS) was determined from the date of histological confirmed STS diagnosis to the time of STS death. To assess the independent value of different pretreatment variables on survival, in the presence of other variables, multivariate analysis was performed using the Cox proportional hazards model. Only variables with value 0.10 or less from the univariate analysis were entered into the Cox regression analysis. The significance level used in both univariate and multivariate analyses was $\mathrm{P}<0.05$, but in the post hoc subgroup analysis the significance level was moved from $\mathrm{P}=0.05$ to $\mathrm{P}=0.01$ due to risk of false positivity.

\section{Ethical clearance}

The National Cancer Data Inspection Board and The Regional Committee for Research Ethics approved the study. The Regional Committee approved that written consent from the patients for their information to be stored in the hospital database and used for research was not needed because most of the material was more than 20 years old and most of the patients are now dead. The material was collected from our approved biobank for paraffin-embedded material and slides. All material was anonymously collected. The data were analyzed anonymously.

\section{Results}

\section{Clinicopathological variables}

The clinicopathological variables are summarized in Table 1. Median age was 59 (range, 0-91) years and 56\% were female. The non-GIST STS comprised 249 tumors including pleomorphic sarcoma $(\mathrm{n}=68)$, leiomyosarcoma $(\mathrm{n}=$ 67 ), liposarcoma ( $n=34)$, malignant fibroblastic/myofibroblastic tumors $(n=20)$, rhabdomyosarcoma $(n=16)$, synovial sarcoma $(n=16)$, angiosarcoma $(n=13)$, malignant peripheral nerve sheath tumor (MPNST) $(\mathrm{n}=11)$ and other types of sarcoma $(n=4)$. The tumors were localized in the extremities $(n=89)$, viscera $(n=58)$, trunk ( $n$ $=47)$, retroperitoneum $(\mathrm{n}=37)$ and head/neck $(\mathrm{n}=18)$. The treatment option of choice was surgery $(n=228), 120$ patients received surgery alone, 55 patients received surgery and radiotherapy, 40 patients received surgery and chemotherapy and 13 patients received surgery, radiotherapy and chemotherapy. Of the non-operated patients (inoperable, $\mathrm{n}=11$; advanced age/other serious disease, $\mathrm{n}$ $=5$, STS diagnosis confirmed post mortem, $\mathrm{n}=3$; patient refusal, $\mathrm{n}=2$ ) seven received chemotherapy and/or radiotherapy. Fourteen patients did not obtain any treatment.

\section{Interobserver variability}

Interobserver scoring agreement was tested for all markers. The intraclass correlation coefficients were as 

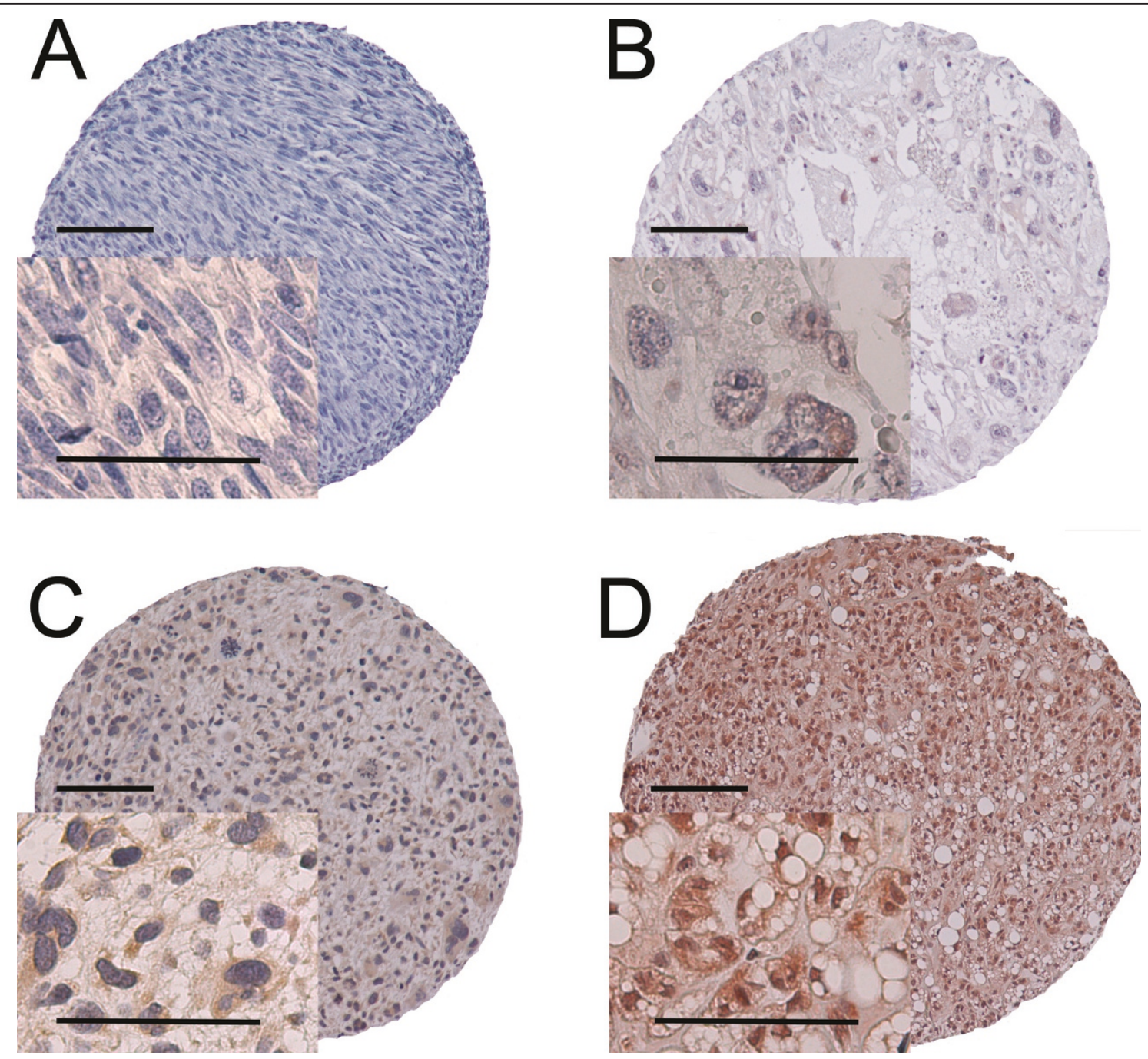

Figure 1 IHC analysis of TMA of non-GIST STS representing different expressions of markers belonging to PI3K/Akt pathway in tumor cells. A, Leiomyosarcoma, histological grade I, PTEN, negative staining, score 0; B, Pleomorphic liposarcoma, histological grade III, p-Akt Thr ${ }^{308}$, weak nuclear staining, score 1; C, Undifferentiated pleomorphic sarcoma, histological grade III, PI3K, moderate cytoplasmic staining; score 2; D, Dedifferentiated liposarcoma, histological grade II, p-Akt Ser ${ }^{473}$, strong both nuclear and cytoplasmic staining, score 3. All calibration bars correspond to $100 \mu \mathrm{m}$ in the overview images (objective 10x) and $50 \mu \mathrm{m}$ in the pictures taken at high magnification (objective 40X). Abbreviations: IHC, immunohistochemistry; TMA, tissue microarray; non-GIST STS, non gastro-intestinal stromal tumor soft-tissue sarcoma; PTEN, phosphatase and tensin homolog; p-Akt Thr ${ }^{308}$, Akt phosphorylated at threonin 308; Pl3K, phosphoinositide 3-kinase; p-Akt Ser ${ }^{473}$, Akt phosphorylated at serin 473 .

follows: 0.89 for p-Akt $\operatorname{Ser}^{473}$ (p < 0.001), 0.94 for p-Akt $\mathrm{Thr}^{308}$ ( $\left.\mathrm{p}<0.001\right), 0.91$ for Akt2 ( $\left.<<0.001\right), 0.95$ for Akt3 ( $<<0.001), 0.88$ for PI3-K ( $<<0.001)$ and 0.89 for PTEN $(\mathrm{p}<0.001)$.

\section{Expression pattern and correlations with clinicopathological variables}

In the immunohistochemical analyses, we used antibodies against all Akt isoforms, including Akt phosphorylated at $\mathrm{Ser}^{473}$ and at $\mathrm{Thr}^{308}$, non-phosphorylated Akt2 and total (both phosphorylated and non-phosphorylated) Akt3. Besides, we investigated expression of total PI3K and PTEN. The p-Akt Ser ${ }^{473}$, p-Akt Thr ${ }^{308}$, Akt2, Akt3, PI3K and PTEN showed expression in the cytoplasm or both in the cytoplasm and in the nuclei of tumor cells in the majority of cases, while pure nuclear staining was demonstrated in a smaller proportion of the tumors, varying from $7 \%$ of all immunohistochemically positive tumors for PTEN to $19 \%$ for p-Akt $\mathrm{Thr}^{308}$ and Akt3.

Expression of p-Akt $\operatorname{Ser}^{473}(\mathrm{r}=0.179, \mathrm{P}=0.005)$, $\mathrm{p}$ Akt $\mathrm{Thr}^{308}(\mathrm{r}=0.150, \mathrm{P}=0.019)$, Akt2 $(\mathrm{r}=0.250, \mathrm{p}<$ $0.001)$ and PI3K $(r=0.223, p<0.001)$ correlated significantly positive with STS histological grade. PI3K and pAkt $\mathrm{Thr}^{308}$ positivity in STSs correlated with presence 
Table 1 Clinicopathological variables as predictors for disease-specific survival in 249 non-GIST STSs (univariate analyses, log-rank test).

\begin{tabular}{|c|c|c|c|c|c|}
\hline Characteristic & $\begin{array}{l}\text { Patients } \\
\text { (n) }\end{array}$ & $\begin{array}{l}\text { Patients } \\
(\%)\end{array}$ & $\begin{array}{l}\text { Median survival } \\
\text { (months) }\end{array}$ & $\begin{array}{c}5 \text {-Year survival } \\
(\%)\end{array}$ & $\mathbf{P}$ \\
\hline \multicolumn{6}{|l|}{ Age } \\
\hline$\leq 60$ years & 133 & 53 & 59 & 50 & 0.065 \\
\hline$>60$ years & 116 & 47 & 30 & 40 & \\
\hline \multicolumn{6}{|l|}{ Gender } \\
\hline Male & 110 & 44 & 41 & 46 & 0.390 \\
\hline Female & 139 & 56 & 45 & 45 & \\
\hline \multicolumn{6}{|l|}{ Patient nationality } \\
\hline Norwegian & 167 & 67 & 63 & 51 & 0.011 \\
\hline Russian & 82 & 33 & 22 & 34 & \\
\hline \multicolumn{6}{|l|}{ Histological entity } \\
\hline Pleomorphic sarcoma & 68 & 27 & 29 & 40 & 0.102 \\
\hline Leiomyosarcoma & 67 & 27 & 45 & 46 & \\
\hline Liposarcoma & 34 & 14 & NR & 67 & \\
\hline MF/MFT & 20 & 8 & 43 & 50 & \\
\hline Angiosarcoma & 13 & 5 & 10 & 31 & \\
\hline Rhabdomyosarcoma & 16 & 6 & 17 & 38 & \\
\hline MPNST & 11 & 5 & 49 & 45 & \\
\hline Synovial sarcoma & 16 & 6 & 31 & 29 & \\
\hline Other STSs & 4 & 2 & NR & 18 & \\
\hline \multicolumn{6}{|l|}{ Tumor localization } \\
\hline Extremities & 89 & 36 & 100 & 53 & 0.348 \\
\hline Trunk & 47 & 29 & 32 & 44 & \\
\hline Retroperitoneum & 37 & 25 & 25 & 38 & \\
\hline Head/Neck & 18 & 7 & 15 & 41 & \\
\hline Visceral & 58 & 23 & 30 & 42 & \\
\hline \multicolumn{6}{|l|}{ Tumor size } \\
\hline$\leq 5 \mathrm{~cm}$ & 74 & 30 & 127 & 57 & 0.027 \\
\hline $5-10 \mathrm{~cm}$ & 91 & 37 & 44 & 45 & \\
\hline$>10 \mathrm{~cm}$ & 81 & 32 & 28 & 36 & \\
\hline Missing & 3 & 1 & & & \\
\hline \multicolumn{6}{|l|}{ Malignancy grade } \\
\hline 1 & 61 & 25 & NR & 74 & $<0.001$ \\
\hline 2 & 98 & 39 & 41 & 45 & \\
\hline 3 & 90 & 36 & 16 & 26 & \\
\hline \multicolumn{6}{|l|}{ Tumor depth } \\
\hline Superficial & 17 & 7 & NR & 93 & $<0.001$ \\
\hline Deep & 232 & 93 & 36 & 42 & \\
\hline \multicolumn{6}{|c|}{ Metastasis at the time of diagnosis } \\
\hline No & 206 & 83 & 76 & 53 & $<0.001$ \\
\hline Yes & 43 & 17 & 10 & 10 & \\
\hline \multicolumn{6}{|l|}{ Surgery } \\
\hline Yes & 228 & 92 & 59 & 50 & $<0.001$ \\
\hline No & 21 & 8 & 5 & 0 & \\
\hline \multicolumn{6}{|l|}{ Resection margins } \\
\hline Free & 178 & 71 & 127 & 66 & $<0.001$ \\
\hline Not free/no surgery & 71 & 29 & 10 & 18 & \\
\hline \multicolumn{6}{|l|}{ Chemotherapy } \\
\hline No & 191 & 77 & 52 & 47 & 0.424 \\
\hline Yes & 58 & 23 & 29 & 40 & \\
\hline
\end{tabular}

Radiotherapy 
Table 1 Clinicopathological variables as predictors for disease-specific survival in 249 non-GIST STSs (univariate analyses, log-rank test). (Continued)

\begin{tabular}{|c|c|c|c|c|c|}
\hline No & 176 & 71 & 48 & 46 & 0.590 \\
\hline Yes & 73 & 29 & 38 & 43 & \\
\hline
\end{tabular}

Abbreviations: non-GIST STS, non-gastro intestinal stromal tumor soft-tissue sarcoma; NR, not reached; MF/MFT, malignant fibroblastic/myofibroblastic tumors; MPNST, malignant peripheral nerve sheath tumor

of metastasis at the time of diagnosis. Strong expression of p-Akt $\mathrm{Thr}^{308}$ was observed in $69 \%$ of the metastasizing tumors, whereas only $41 \%$ of non-metastasizing STSs $(r=0.208, P=0.001)$ were strongly positive for this marker. For PI3K, the metastasizing versus nonmetastasizing characteristics comprised $78 \%$ and $53 \%$, respectively $(r=0.188, P=0.003)$. None of the investigated markers correlated significantly with age, gender, tumor location, depth, size or relapse rate.

\section{Univariate analyses}

Data are presented in Table 1 . Patient nationality $(\mathrm{P}=$ $0.011)$, tumor size $(\mathrm{P}=0.027)$, malignancy grade $(\mathrm{p}<$ $0.001)$, tumor depth $(\mathrm{p}<0.001)$, metastasis at time of diagnosis $(p<0.001)$, surgery $(p<0.001)$ and resection margins $(p<0.001)$ were all significant prognostic variables for DSS.

The prognostic impact of the investigated molecular factors is shown in Table 2. Among these, p-Akt Thr ${ }^{308}$ $(\mathrm{P}=0.002)$, Akt2 $(\mathrm{P}=0.008)$ and PI3K $(\mathrm{p}<0.001)$ were significant indicators of shorter DSS, Figure 2, A-C.

In order to find out whether subcellular location of proteins belonging to the Akt/PI3K signaling pathway has impact on survival, we performed a series of univariate analyses to compare the impact of their expression in nucleus, cytoplasm or both. Nuclear expression of pAkt $\mathrm{Thr}^{308}$ expression showed a significantly favorable prognosis $(\mathrm{P}=0.029)$, compared to cytoplasmic and

Table 2 Tumor expression of markers belonging to PI3K/Akt signaling pathway and their prognostic impact on disease-specific survival in patients with non-GIST STSs (univariate analyses; log-rank test, $n=249$ ), for all patients and separately for men and women.

\begin{tabular}{|c|c|c|c|c|c|c|c|c|c|c|c|c|}
\hline \multirow[t]{2}{*}{ Marker expression } & \multicolumn{3}{|c|}{ Patients, n (\%) } & \multicolumn{3}{|c|}{$\begin{array}{l}\text { Median survival } \\
\text { (months) }\end{array}$} & \multicolumn{3}{|c|}{ 5-Year survival (\%) } & \multicolumn{3}{|c|}{$P$} \\
\hline & A & $M$ & W & A & $M$ & W & A & $M$ & W & A & $M$ & W \\
\hline \multicolumn{13}{|l|}{ p-Akt Thr ${ }^{308}$} \\
\hline Low & $131(53)$ & $59(55)$ & $72(52)$ & 91 & $N R$ & 80 & 55 & 56 & 54 & 0.002 & 0.009 & 0.064 \\
\hline High & $113(45)$ & $48(44)$ & $65(47)$ & 29 & 26 & 31 & 35 & 33 & 36 & & & \\
\hline Missing & $5(2)$ & $3(1)$ & $2(1)$ & & & & & & & & & \\
\hline \multicolumn{13}{|l|}{ p-Akt Ser ${ }^{473}$} \\
\hline Low & $70(28)$ & $35(32)$ & $35(25)$ & 62 & 41 & 127 & 51 & 45 & 57 & 0.074 & 0.868 & 0.023 \\
\hline High & $174(70)$ & $74(67)$ & $100(72)$ & 31 & 41 & 29 & 43 & 46 & 40 & & & \\
\hline Missing & $5(2)$ & $1(1)$ & $4(3)$ & & & & & & & & & \\
\hline \multicolumn{13}{|l|}{ Akt2 } \\
\hline Low & 82 (33) & 41 (37) & 41 (39) & 123 & $N R$ & 80 & 58 & 56 & 59 & 0.008 & 0.062 & 0.064 \\
\hline High & $163(65)$ & $68(62)$ & $95(68)$ & 31 & 31 & 31 & 41 & 42 & 40 & & & \\
\hline Missing & $4(2)$ & $1(1)$ & $3(3)$ & & & & & & & & & \\
\hline \multicolumn{13}{|l|}{ Akt3 } \\
\hline Low & $177(71)$ & $81(74)$ & $96(69)$ & 62 & 63 & 57 & 51 & 51 & 50 & 0.067 & 0.207 & 0.197 \\
\hline High & $60(24)$ & $22(20)$ & 38 (27) & 31 & 27 & 38 & 35 & 33 & 36 & & & \\
\hline Missing & $12(5)$ & $7(6)$ & $5(4)$ & & & & & & & & & \\
\hline \multicolumn{13}{|l|}{ PI3K } \\
\hline Negative & $104(42)$ & $44(40)$ & $60(43)$ & NR & $N R$ & 127 & 60 & 57 & 63 & $<0.001$ & 0.078 & $<0.001$ \\
\hline Positive & $136(56)$ & $61(55)$ & 75 (54) & 29 & 37 & 23 & 37 & 41 & 33 & & & \\
\hline Missing & $9(4)$ & $5(5)$ & $4(3)$ & & & & & & & & & \\
\hline \multicolumn{13}{|l|}{ PTEN } \\
\hline Negative & 88 (35) & 37 (34) & 51 (37) & 80 & $N R$ & 80 & 51 & 51 & 51 & 0.259 & 0.658 & 0.198 \\
\hline Positive & $148(59)$ & $67(61)$ & 81 (58) & 41 & 41 & 38 & 46 & 48 & 44 & & & \\
\hline Missing & $13(6)$ & $5(5)$ & $7(5)$ & & & & & & & & & \\
\hline
\end{tabular}




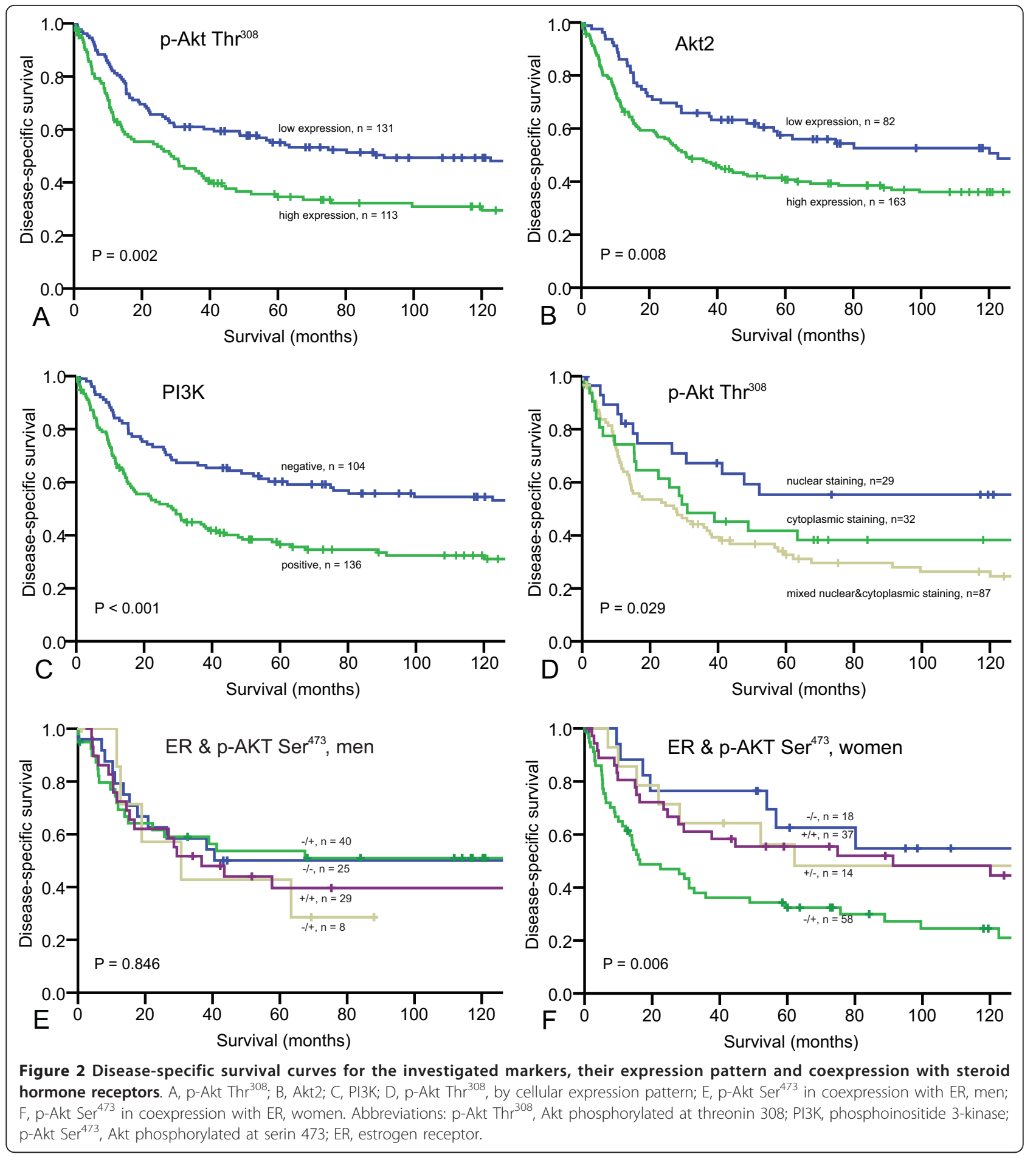

especially mixed cytoplasmic and nuclear expression, Figure 2, D. The other factors did not show any significant prognostic differences in the subcellular location.

Subgroup analysis based on clinical variables revealed that high expression of both p-Akt $\mathrm{Thr}^{308}(\mathrm{P}=0.006)$ and Akt3 $(\mathrm{P}=0.001)$ were adverse prognostic indicators for STSs located to extremities and for tumors larger than $5 \mathrm{~cm}$ in largest dimension $(\mathrm{P}=0.001$ for both markers). Interestingly, high expression of p-Akt $\mathrm{Thr}^{308}$ was a negative prognostic factor particularly for men $(\mathrm{P}=$ 0.009 vs. $\mathrm{P}=0.064$ for women). In contrast, $\mathrm{p}$-Akt $\mathrm{Ser}^{473}$, which appeared to be a negative prognosticator exclusively for female patients $(\mathrm{P}=0.023$ vs. $\mathrm{P}=0.868$ for men), Table 2. 


\section{Multivariate Cox proportional hazards analyses}

The results of the multivariate analysis are presented in Table 3. Advanced age of the patient $(\mathrm{P}=0.038)$, deep site $(P=0.018)$, high malignancy grade $(\mathrm{p}<0.001)$, metastasis at time of diagnosis $(\mathrm{P}=0.010)$, lack of surgery $(P=0.031)$, non-free resection margins $(\mathrm{p}<0.001)$, and PI3K expression by tumor cells $(\mathrm{P}=0.042)$ were significant independent negative prognostic indicators of DSS.

\section{Co-expression of activated Akt and PI3K with female steroid hormone receptors}

The co-expression profiles of both types of activated Akt and PI3K with female steroid hormone receptors, in the group as a whole and stratified into gender were tested as shown in Table 4. The co-expression phenotypes PgR $+/$ p-Akt $\mathrm{Thr}^{308}+$ among men $(\mathrm{P}=0.023, \mathrm{HR}=2.4,95 \%$ $\mathrm{CI}=1.1-5.2), \mathrm{ER}-/ \mathrm{PI} 3 \mathrm{~K}+$ both in whole cohort $(\mathrm{P}=$ $0.005, \mathrm{HR}=2.0,95 \% \mathrm{CI}=1.2-3.2)$ and among women $(\mathrm{P}=0.014, \mathrm{HR}=2.4,95 \% \mathrm{CI}=1.2-4.8)$, as well as PgR- $/$ PI3K+ $(\mathrm{P}=0.007, \mathrm{HR}=1.9,95 \% \mathrm{CI}=1.2-3.0)$ and $\mathrm{PgR}+/ \mathrm{PI} 3 \mathrm{~K}+(\mathrm{P}=0.014, \mathrm{HR}=1.9,95 \% \mathrm{CI}=1.1-$ 3.2) in the whole cohort of patients were significant independent negative prognostic factors. Interestingly,

Table 3 Results of the Cox regression analysis summarizing significant independent prognostic factors in the overall material.

\begin{tabular}{|c|c|c|c|}
\hline Factor & Hazard Ratio & $95 \% \mathrm{Cl}$ & $P$ \\
\hline \multicolumn{4}{|l|}{ Age } \\
\hline$\leq 60$ & 1.0 & & \\
\hline$>60$ & 1.5 & $1.0-2.1$ & 0.038 \\
\hline \multicolumn{4}{|l|}{ Tumor depth } \\
\hline Superficial & 1.0 & & \\
\hline Deep & 11 & $1.5-79$ & 0.018 \\
\hline Malignancy grade & & & $<0.001^{*}$ \\
\hline 1 & 1.0 & & \\
\hline 2 & 2.4 & $1.3-4.2$ & 0.003 \\
\hline 3 & 3.7 & $2.1-6.6$ & $<0.001$ \\
\hline \multicolumn{4}{|c|}{ Metastasis at the time of diagnosis } \\
\hline No & 1.0 & & \\
\hline Yes & 1.9 & $1.2-3.1$ & 0.010 \\
\hline \multicolumn{4}{|l|}{ Surgery } \\
\hline Yes & 1.0 & & \\
\hline No & 2.2 & $1.1-4.4$ & 0.031 \\
\hline \multicolumn{4}{|l|}{ Resection-margins } \\
\hline Free & 1.0 & & \\
\hline Non-free & 2.5 & $1.6-3.8$ & $<0.001$ \\
\hline \multicolumn{4}{|l|}{$\mathrm{PI} 3 \mathrm{~K}$} \\
\hline Negative & 1.0 & & \\
\hline Positive & 1.5 & $1.0-2.2$ & 0.042 \\
\hline
\end{tabular}

Abbreviations: PI3K, phosphoinositide-3-kinase.

* Overall significance as a prognostic factor both steroid hormone receptors and Akt phosphorylation site seem to have opposite prognostic impact depending on the gender. This was further proved by the co-expression of these factors. Indeed, PgR-/p-Akt $\mathrm{Ser}^{473}+$ phenotype tended to have an unfavorable impact in women $(\mathrm{P}=0.087)$ but was favorable in men $(\mathrm{P}=$ 0.010). Co-expression of ER and p-Akt Ser ${ }^{473}$ showed similar results, with significantly adverse influence of $-/+$ profile on DSS among female patients $(P=0.006)$. There was no significant difference among the four possible profiles in men, but the $-1+$ curve demonstrated the best survival rate, Figure $2 \mathrm{E}$ and $2 \mathrm{~F}$.

\section{Discussion}

In this large-scale retrospective study we have investigated the prognostic impact of a set of biomarkers belonging to the Akt-PI3K signaling pathway in nonGIST STS patients, both separately and in relation to gender. Further, we have also elucidated the coexpression of these markers and the female hormone receptors ER and PgR. These proteins participate in a diversity of processes in physiological and pathological conditions, especially in cancer development and progression [14]. p-Akt $\mathrm{Thr}^{308}$, Akt2 and PI3K showed significant unfavorable influence on survival of the whole cohort of patients in univariate analyses and, in addition, high expression of PI3K was a significant independent negative prognostic factor. p-Akt $\mathrm{Thr}^{308}$ expression had a strong unfavorable impact among men, but was not significant in women. $\mathrm{p}$ Akt Ser $^{473}$ expression had strong adverse impact in women but was not significant in men or in the whole cohort. PgR-/p-Akt Ser ${ }^{473}$ + phenotype showed less favorable impact in women, but was the most favorable one in men. To our knowledge, this is the first prognostic evaluation of these biomarkers in non-GIST STSs.

Akt, aka protein kinase B, is a serine/threonine protein kinase. Currently, three mammalian isoforms (Akt1/ $\mathrm{PKB} \alpha, A k t 2 / \mathrm{PKB} \beta$, and $A k \mathrm{t} 3 / \mathrm{PKB} \gamma$ ) have been identified. They are encoded by different genes and have different tissue distribution [29].

In a healthy organism, Akt1 is a key signaling protein in the cellular pathways that result in skeletal muscle hypertrophy, and general tissue growth [30]. Akt can be phosphorylated by its two activating kinases, phosphoinositide dependent kinase 1 (PDK1) - at threonine ${ }^{308}$, and mammalian target of rapamycin complex 2 (mTORC2), previously putatively named PDK2, - at serine ${ }^{473}$. Both mTORC2 and PDK1 are products of the PI3K pathway. Activated Akt can activate or deactivate its multiple substrates, including mammalian target of rapamycin (mTOR), bcl-2 family member BAD, transcription factor forkhead homolog 1 in rhabdomyosarcoma (FKHR), Mdm2 protein, glycogen synthase kinase 3 (GSK3) and many others, via its kinase activity [31,32]. 
Table 4 Co-expression of activated AKT and PI3K with ER and PGR and their prediction for DSS in patients with nonGIST STSs (univariate analyses; log-rank test, $n=249$, only significant combinations are represented) and results of Cox regression analysis (multivariate analyses).

\begin{tabular}{|c|c|c|c|c|c|c|c|c|}
\hline \multicolumn{6}{|c|}{ Univariate analyses } & \multicolumn{3}{|c|}{ Multivariate analyses } \\
\hline $\begin{array}{c}\text { Markers } \\
\text { coexpression }\end{array}$ & $\begin{array}{l}\text { Patients } \\
\text { (n) }\end{array}$ & $\begin{array}{l}\text { Patients } \\
\text { (\%) }\end{array}$ & $\begin{array}{l}\text { Median survival } \\
\text { (months) }\end{array}$ & $\begin{array}{c}5 \text {-Year survival } \\
(\%)\end{array}$ & $P$ & Hazard ratio & $95 \% \mathrm{Cl}$ & $P$ \\
\hline \multicolumn{9}{|c|}{ ER/p-Akt Thr ${ }^{308}$ all } \\
\hline$-/-$ & 83 & 33 & 127 & 57 & 0.002 & & & NS \\
\hline$-/+$ & 58 & 23 & 18 & 29 & & & & \\
\hline$+/-$ & 42 & 17 & 63 & 54 & & & & \\
\hline$+/+$ & 47 & 19 & 45 & 46 & & & & \\
\hline Missing & 19 & 8 & & & & & & \\
\hline \multicolumn{9}{|c|}{ ER/p-Akt Thr ${ }^{308}$ women } \\
\hline$-/-$ & 42 & 30 & 57 & 50 & 0.012 & & & NS \\
\hline$-/+$ & 35 & 25 & 16 & 27 & & & & \\
\hline$+/-$ & 27 & 19 & 91 & 59 & & & & \\
\hline$+/+$ & 25 & 19 & 120 & 53 & & & & \\
\hline Missing & 11 & 7 & & & & & & \\
\hline \multicolumn{9}{|c|}{ PgR/p-Akt Thr ${ }^{308}$ all } \\
\hline$-/-$ & 101 & 41 & 127 & 59 & 0.014 & & & NS \\
\hline$-/+$ & 62 & 25 & 26 & 38 & & & & \\
\hline$+/-$ & 26 & 10 & 54 & 46 & & & & \\
\hline$+/+$ & 49 & 20 & 32 & 32 & & & & \\
\hline Missing & 11 & 4 & & & & & & \\
\hline \multicolumn{9}{|c|}{ PgR/p-Akt Thr ${ }^{308}$ men } \\
\hline$-/-$ & 49 & 45 & NR & 64 & 0.003 & 1.0 & & $0.099^{*}$ \\
\hline$-/+$ & 30 & 27 & 29 & 43 & & 2.0 & $1.0-4.1$ & 0.047 \\
\hline$+/-$ & 8 & 7 & 15 & 25 & & 1.8 & $0.65-4.8$ & 0.261 \\
\hline$+/+$ & 17 & 16 & 17 & 18 & & 2.4 & $1.1-5.2$ & 0.023 \\
\hline Missing & 6 & 5 & & & & & & \\
\hline \multicolumn{9}{|c|}{ ER/p-Akt Ser ${ }^{473}$ women } \\
\hline$-/-$ & 18 & 13 & 127 & 63 & 0.006 & & & NS \\
\hline$-/+$ & 58 & 41 & 16 & 32 & & & & \\
\hline$+/-$ & 14 & 10 & 62 & 56 & & & & \\
\hline +/+ & 37 & 27 & 91 & 55 & & & & \\
\hline Missing & 13 & 9 & & & & & & \\
\hline \multicolumn{9}{|c|}{ PgR/p-Akt Ser ${ }^{473}$ men } \\
\hline$-/-$ & 29 & 27 & NR & 55 & 0.010 & 1.0 & & $0.022^{*}$ \\
\hline$-/+$ & 51 & 47 & $N R$ & 57 & & 1.1 & $0.54-2.4$ & 0.744 \\
\hline$+/-$ & 4 & 4 & 21 & 0 & & 6.7 & $1.9-24$ & 0.003 \\
\hline$+/+$ & 21 & 19 & 15 & 24 & & 1.5 & $0.67-3.2$ & 0.329 \\
\hline Missing & 5 & 5 & & & & & & \\
\hline \multicolumn{9}{|l|}{ ER/PI3K all } \\
\hline$-/-$ & 65 & 27 & 127 & 60 & 0.002 & 1.0 & & $0.032^{*}$ \\
\hline$-1+$ & 73 & 29 & 18 & 36 & & 2.0 & $1.2-3.2$ & 0.005 \\
\hline$+/-$ & 33 & 13 & NR & 63 & & 1.1 & $0.56-2.1$ & 0.816 \\
\hline$+/+$ & 56 & 22 & 37 & 43 & & 1.4 & $0.83-2.4$ & 0.200 \\
\hline Missing & 22 & 9 & & & & & & \\
\hline \multicolumn{9}{|l|}{ ER/PI3K women } \\
\hline$-/-$ & 33 & 24 & 100 & 59 & $<0.001$ & 1.0 & & $0.036^{*}$ \\
\hline$-/+$ & 42 & 30 & 15 & 25 & & 2.4 & $1.2-4.8$ & 0.014 \\
\hline$+/-$ & 23 & 16 & $N R$ & 70 & & 0.9 & $0.36-2.0$ & 0.715 \\
\hline +/+ & 29 & 21 & 29 & 46 & & 1.5 & $0.72-3.0$ & 0.290 \\
\hline
\end{tabular}


Table 4 Co-expression of activated AKT and PI3K with ER and PGR and their prediction for DSS in patients with nonGIST STSs (univariate analyses; log-rank test, $n=249$, only significant combinations are represented) and results of Cox regression analysis (multivariate analyses). (Continued)

\begin{tabular}{|c|c|c|c|c|c|c|c|c|}
\hline \multicolumn{9}{|l|}{ PgR/PI3K all } \\
\hline$-/-$ & 76 & 31 & NR & 62 & 0.001 & 1.0 & & $0.032^{*}$ \\
\hline$-/+$ & 86 & 35 & 29 & 43 & & 1.9 & $1.2-3.0$ & 0.007 \\
\hline$+/-$ & 26 & 10 & 100 & 58 & & 1.3 & $0.69-2.5$ & 0.397 \\
\hline$+/+$ & 46 & 18 & 31 & 27 & & 1.9 & $1.1-3.2$ & 0.014 \\
\hline Missing & 15 & 6 & & & & & & \\
\hline \multicolumn{9}{|l|}{ PgR/PI3K men } \\
\hline$-/-$ & 36 & 34 & NR & 65 & 0.014 & & & NS \\
\hline$-1+$ & 44 & 40 & 63 & 51 & & & & \\
\hline$+/-$ & 7 & 6 & 21 & 29 & & & & \\
\hline$+/+$ & 15 & 14 & 17 & 20 & & & & \\
\hline Missing & 7 & 6 & & & & & & \\
\hline \multicolumn{9}{|c|}{ PgR/PI3K women } \\
\hline$-/-$ & 40 & 29 & 80 & 59 & 0.007 & & & NS \\
\hline$-/+$ & 42 & 30 & 17 & 36 & & & & \\
\hline$+/-$ & 19 & 14 & NR & 68 & & & & \\
\hline$+/+$ & 31 & 21 & 31 & 31 & & & & \\
\hline Missing & 8 & 6 & & & & & & \\
\hline
\end{tabular}

Abbreviations: ER, estrogen receptor; PgR, progesterone receptor; NR, not reached; NS, not significant;

* overall significance as a prognostic factor

Akt1 is involved in cellular survival pathways by inhibiting apoptotic processes. Since it thereby promotes cell survival, Akt1 has been regarded as a major factor in many types of cancer [15-17]. The majority of studies agree that high expression of Akt by tumor cells indicates a poor prognosis [19-21]. However, in a recent study by Baba et al., phosphorylated Akt expression was reported to have a favorable impact on DSS in 717 colorectal cancer patients [22]. Similar results were obtained by Mori et al. in a study devoted to Akt expression in endometrial carcinoma [23]. This discrepancy can probably be explained by the site of Akt phosphorylation. Both studies utilized antibodies against p-Akt Ser ${ }^{473}$, while the articles describing negative influence of Akt are based on p-Akt $\mathrm{Thr}^{308}$ expression [20,33,34]. Al-Saad et al. [33] has recently compared the prognostic impact of Akt phosphorylated on both sites and demonstrated that expression of p-Akt $\mathrm{Thr}^{308}$, unlike p-Akt Ser ${ }^{473}$, negatively influenced prognosis in patients with non-small cell lung cancer.

For the whole cohort we also found that p-Akt $\mathrm{Thr}^{308}$ expression was associated with a shorter STS survival in univariate analyses, while p-Akt $\mathrm{Ser}^{473}$ expression had no significant value. However, calculated separately for each gender, high expression of p-Akt $\mathrm{Thr}^{308}$ was a negative prognostic factor particularly for men, in contrast to p-Akt Ser ${ }^{473}$, which appeared to be a negative prognosticator exclusively for female patients. This prompted us to further investigate this phenomenon by studying of co-expression profiles of both types of activated Akt with female steroid hormone receptors. In our previous works we have shown that ER and PgR expression possess variable prognostic significance depending of gender both per se [25] and in co-expression with TGF- $\beta$ and fascin [26]. ER $\beta$ was shown to activate PI3K/Akt signalling pathway [35]. Tsai et al. demonstrated an activation of Akt by estrogen in ER negative breast cancer cell culture [36]. In the present study, the prognostic diversity of these factors in men and women was enhanced in the co-expression profiles: male patients with STSs expressing simultaneously pAkt $\mathrm{Thr}^{308}$ and PgR had statistically significant minimal survival rate. For women, the ER-/p-Akt Ser ${ }^{473}+$ expression profile was the most unfavorable phenotype.

Taking into consideration a possible distortion of the results by gender-related sarcomas (i.e. leiomyosarcoma in uterus) we have attempted to exclude these sarcomas and recalculate all analyses. There were no considerable differences in the results by exclusion of gender-related sarcomas comparing to those obtained for whole cohort (data not shown).

Akt2 is an important molecule in the insulin signaling pathway, but in Akt1 deficient mice it is also proved to substitute, at least partly, the role of Akt1 in growth and proliferation [37]. We found Akt2 expression to be associated with significantly shorter DSS in univariate analysis. This might be explained by the extra-endocrine function of Akt2. The role of Akt3 is less clear, it 
appears to be predominantly expressed in the central nervous system [29]. In this study, we failed to demonstrate any association of Akt3 with the survival of STS patients.

PI3K is, via PDK1 and mTORC2 dependent activation, an upstream regulator of all Akt isoforms, and plays an important role in the PI3K/Akt pathway. Its high expression has been implicated as an adverse prognostic factor in many types of cancer [38-40]. In STS, we observed that PI3K expression was an independent significant indicator of shorter DSS. Not surprisingly, the co-expression of PI3K with both ER and PgR showed multiple independent negative impacts on survival in STS patients with the phenotypes ER-/PI3K+ in women and $\mathrm{PgR}+/ \mathrm{PI} 3 \mathrm{~K}+$ in men being the least favorable.

The tumor suppressor gene PTEN negatively regulates the PI3K/Akt signaling pathway. It is a proapoptotic and antineoplastic factor and shown to be a favorable prognosticator in cancer patients [41]. In our study, we failed to find any statistical difference in survival between patients having PTEN-positive and PTEN-negative STSs.

In our material, all investigated factors showed three distinct patterns of expression; nuclear, cytoplasmic and combined nuclear and cytoplasmic. Little is known about the prognostic value of such subcellular stratification. Le Page et al. reported that nuclear Akt-1 and Akt2 expression were significantly correlated with favorable outcome in 63 prostate cancer patients, while cytoplasmic Akt-1 expression was correlated with a higher risk of postoperative prostate-specific antigen (PSA) recurrence and shorter PSA recurrence interval [42]. In the present study, we were able to find such dependence only for nuclear $\mathrm{p}$-Akt $\mathrm{Thr}^{308}$ expression, which proved to be prognostically favorable compared to cytoplasmic and especially mixed cytoplasmic and nuclear location.

\section{Conclusion}

We have characterized the occurrence and distribution of several proteins belonging to PI3K/Akt signaling pathway in STS patients with respect to tumor aggressiveness and DSS. Our findings are largely in agreement with the results of a number of studies that have investigated the roles of these markers in other, especially epithelial, tumors. Nevertheless, the diverse prognostic values depending on the site of Akt phosphorylation and on the co-expression with female steroid hormones have not been described earlier.

Our findings may help to identify subgroups of patients with aggressive tumors requiring adjuvant therapy which, due to relationship of the PI3K/Akt pathway components with female steroid hormone receptor proteins, could include specific endocrine treatment. Moreover, since the investigated biomarkers belong to the family of serine-threonine kinases, which are comprehended as "drugable"[18], they may represent molecular targets for personalized, small-molecule targeted therapy. This currently is a hotspot of oncological research, and it was shown effect of such Akt targeted agents on several subtypes of sarcomas in vitro $[43,44]$.

\section{Acknowledgements}

This study was funded by the Helse Nord, The Norwegian Childhood Cancer Network, The Norwegian Sarcoma Group and The Norwegian Cancer Society. The funders had no role in study design, data collection and analysis, decision to publish, or preparation of the manuscript. We are grateful to Frode Skjold for establishing functional connections between the databases and Magnus L. Persson for making the TMA blocks.

\section{Author details}

${ }^{1}$ Dept of Clinical Pathology, University Hospital of Northern Norway, Troms $\varnothing$, Norway. ${ }^{2}$ Institute of Medical Biology, University of Tromsø, Norway. ${ }^{3}$ Dept of Oncology, University Hospital of Northern Norway, Tromsø, Norway.

${ }^{4}$ Institute of Clinical Medicine, University of Tromsø, Norway.

\section{Authors' contributions}

AV, SWS, TKK, TD, RMB and LTB participated in the design of the study. AV ES and TKK collected clinical information. AV and SWS reviewed all the histological diagnoses, histological grading, selected and marked the slides for TMA construction. AV, TKK and SWS performed the experiments. AV, TKK, SWS, TD, RMB and LTB performed the statistical analysis. AV, TK, SWS, TD, ES and LTB contributed reagents/materials/analysis tools. AV, TD, ES, RMB and LTB drafted the manuscript. All authors read and approved the final manuscript.

\section{Competing interests}

The authors declare that they have no competing interests.

Received: 30 July 2011 Accepted: 22 November 2011

Published: 22 November 2011

\section{References}

1. Gustafson P: Soft tissue sarcoma. Epidemiology and prognosis in 508 patients. Acta Orthop Scand Supp/ 1994, 259:1-31.

2. Wibmer C, Leithner A, Zielonke N, Sperl M, Windhager R: Increasing incidence rates of soft tissue sarcomas? A population-based epidemiologic study and literature review. Ann Oncol 2010, 21:1106-1111.

3. Engellau J, Anderson H, Rydholm A, Bauer HC, Hall KS, Gustafson P, et al: Time dependence of prognostic factors for patients with soft tissue sarcoma: a Scandinavian Sarcoma Group Study of 338 malignant fibrous histiocytomas. Cancer 2004, 100:2233-2239.

4. Dickinson IC, Whitwell DJ, Battistuta D, Thompson B, Strobel N, Duggal A, et al: Surgical margin and its influence on survival in soft tissue sarcoma. ANZ J Surg 2006, 76:104-109.

5. Zagars GK, Ballo MT, Pisters PW, Pollock RE, Patel SR, Benjamin RS: Prognostic factors for disease-specific survival after first relapse of softtissue sarcoma: analysis of 402 patients with disease relapse after initial conservative surgery and radiotherapy. Int J Radiat Oncol Biol Phys 2003, 57:739-747.

6. Raney RB Jr, Crist WM, Maurer HM, Foulkes MA: Prognosis of children with soft tissue sarcoma who relapse after achieving a complete response. A report from the Intergroup Rhabdomyosarcoma Study I. Cancer 1983, 52:44-50.

7. Kiatisevi P, Asavamongkolkul A, Phimolsarnti R, Waikakul S, Benjarassamerote $S$ : The outcomes and prognostic factors of patients with soft-tissue sarcoma. J Med Assoc Thai 2006, 89:334-342.

8. Yang RS, Lane JM, Eilber FR, Dorey FJ, al Shaikh R, Schumacher LY, et al: High grade soft tissue sarcoma of the flexor fossae. Size rather than compartmental status determine prognosis. Cancer 1995, 76:1398-1405.

9. Mendenhall WM, Zlotecki RA, Hochwald SN, Hemming AW, Grobmyer SR, Cance WG: Retroperitoneal soft tissue sarcoma. Cancer 2005, 104:669-675. 
10. Koea JB, Leung D, Lewis JJ, Brennan MF: Histopathologic type: an independent prognostic factor in primary soft tissue sarcoma of the extremity? Ann Surg Oncol 2003, 10:432-440.

11. Guillou L, Aurias A: Soft tissue sarcomas with complex genomic profiles. Virchows Arch 2009.

12. Verweij J, Baker LH: Future treatment of soft tissue sarcomas will be driven by histological subtype and molecular aberrations. Eur J Cancer 2010, 46:863-868.

13. Beck $A H$, West RB, van de RM: Gene expression profiling for the investigation of soft tissue sarcoma pathogenesis and the identification of diagnostic, prognostic, and predictive biomarkers. Virchows Arch 2010, 456:141-151.

14. Franke TF, Kaplan DR, Cantley LC: PI3K: downstream AKTion blocks apoptosis. Cell 1997, 88:435-437.

15. Hager M, Haufe H, Kemmerling R, Hitzl W, Mikuz G, Moser PL, et al: Increased activated Akt expression in renal cell carcinomas and prognosis. J Cell Mol Med 2009, 13:2181-2188.

16. Woenckhaus J, Steger K, Sturm K, Munstedt K, Franke FE, Fenic I: Prognostic value of PIK3CA and phosphorylated AKT expression in ovarian cancer. Virchows Arch 2007, 450:387-395.

17. Tang JM, He QY, Guo RX, Chang XJ: Phosphorylated Akt overexpression and loss of PTEN expression in non-small cell lung cancer confers poor prognosis. Lung Cancer 2006, 51:181-191.

18. Hennessy BT, Smith DL, Ram PT, Lu Y, Mills GB: Exploiting the PI3K/AKT pathway for cancer drug discovery. Nat Rev Drug Discov 2005, 4:988-1004.

19. Maniscalco L, lussich S, Martin de Las MJ, Millan Y, Biolatti B, Sasaki N, et al: Activation of AKT in feline mammary carcinoma: A new prognostic factor for feline mammary tumours. Vet $J 2011$.

20. Hasselblom S, Hansson U, Olsson M, Toren L, Bergstrom A, Nilsson-Ehle $H_{\text {, }}$ et al: High immunohistochemical expression of $\mathrm{p}$-AKT predicts inferior survival in patients with diffuse large B-cell lymphoma treated with immunochemotherapy. Br J Haematol 2010, 149:560-568.

21. Yoshioka A, Miyata H, Doki Y, Yasuda T, Yamasaki M, Motoori M, et al: The activation of Akt during preoperative chemotherapy for esophageal cancer correlates with poor prognosis. Oncol Rep 2008, 19:1099-1107.

22. Baba Y, Nosho K, Shima K, Hayashi M, Meyerhardt JA, Chan AT, et al: Phosphorylated AKT expression is associated with PIK3CA mutation, low stage, and favorable outcome in 717 colorectal cancers. Cancer 2010.

23. Mori N, Kyo S, Sakaguchi J, Mizumoto Y, Ohno S, Maida Y, et al: Concomitant activation of AKT with extracellular-regulated kinase 1/2 occurs independently of PTEN or PIK3CA mutations in endometrial cancer and may be associated with favorable prognosiss. Cancer $\mathrm{SCi}$ 2007, 98:1881-1888.

24. Tomita Y, Morooka T, Hoshida Y, Zhang B, Qiu Y, Nakamichi I, et al: Prognostic significance of activated AKT expression in soft-tissue sarcoma. Clin Cancer Res 2006, 12:3070-3077.

25. Valkov A, Sorbye S, Kilvaer TK, Donnem T, Smeland E, Bremnes RM, et al: Estrogen receptor and progesterone receptor are prognostic factors in soft tissue sarcomas. Int J Oncol 2011.

26. Valkov A, Sorbye SW, Kilvaer TK, Donnem T, Smeland E, Bremnes RM, et al: The prognostic impact of TGF-beta1, fascin, NF-kappaB and PKC-zeta expression in soft tissue sarcomas. PLoS One 2011, 6:e17507.

27. In World Health Organization Classification of Tumours. Pathology and Genetics of Tumours of Soft Tissue and Bone. Edited by: Fletcher CDM, Unni KK, Mertens F. Lyon: IARC press; 2002:

28. Bremnes RM, Veve R, Gabrielson E, Hirsch FR, Baron A, Bemis L, et al: Highthroughput tissue microarray analysis used to evaluate biology and prognostic significance of the E-cadherin pathway in non-small-cell lung cancer. J Clin Oncol 2002, 20:2417-2428.

29. Zinda MJ, Johnson MA, Paul JD, Horn C, Konicek BW, Lu ZH, et al: AKT-1, -2 , and -3 are expressed in both normal and tumor tissues of the lung, breast, prostate, and colon. Clin Cancer Res 2001, 7:2475-2479.

30. Glass DJ: PI3 kinase regulation of skeletal muscle hypertrophy and atrophy. Curr Top Microbiol Immunol 2010, 346:267-278.

31. She QB, Solit DB, Ye Q, O'Reilly KE, Lobo J, Rosen N: The BAD protein integrates survival signaling by EGFR/MAPK and PI3K/Akt kinase pathways in PTEN-deficient tumor cells. Cancer Cell 2005, 8:287-297.

32. Stoica BA, Movsesyan VA, Lea PM, Faden Al: Ceramide-induced neuronal apoptosis is associated with dephosphorylation of Akt, BAD, FKHR, GSK3beta, and induction of the mitochondrial-dependent intrinsic caspase pathway. Mol Cell Neurosci 2003, 22:365-382.
33. Al Saad S, Donnem T, Al Shibli K, Persson M, Bremnes RM, Busund LT: Diverse prognostic roles of Akt isoforms, PTEN and PI3K in tumor epithelial cells and stromal compartment in non-small cell lung cancer. Anticancer Res 2009, 29:4175-4183.

34. Chen J, Gomes AR, Monteiro LJ, Wong SY, Wu LH, Ng T, et al: Constitutively nuclear FOXO3a localization predicts poor survival and promotes Akt phosphorylation in breast cancer. PLoS One 2010, 5:e12293.

35. Wang M, Wang Y, Weil B, Abarbanell A, Herrmann J, Tan J, et al: Estrogen receptor beta mediates increased activation of $\mathrm{PI} 3 \mathrm{~K} / \mathrm{Akt}$ signaling and improved myocardial function in female hearts following acute ischemia. Am J Physiol Regul Integr Comp Physiol 2009, 296:R972-R978.

36. Tsai EM, Wang SC, Lee JN, Hung MC: Akt activation by estrogen in estrogen receptor-negative breast cancer cells. Cancer Res 2001, 61:8390-8392.

37. Chen WS, Xu PZ, Gottlob K, Chen ML, Sokol K, Shiyanova T, et al: Growth retardation and increased apoptosis in mice with homozygous disruption of the Akt1 gene. Genes Dev 2001, 15:2203-2208.

38. Kato $S$, lida $S$, Higuchi $T$, Ishikawa $T$, Takagi $Y$, Yasuno M, et al: PIK3CA mutation is predictive of poor survival in patients with colorectal cancer. Int J Cancer 2007, 121:1771-1778.

39. Adams JR, Schachter NF, Liu JC, Zacksenhaus E, Egan SE: Elevated PI3K signaling drives multiple Breast Cancer subtypes. Oncotarget 2011

40. Kim JG, Chae YS, Sohn SK, Kang BW, Moon JH, Lee SJ, et al: Clinical significance of genetic variations in the PI3K/PTEN/AKT/mTOR pathway in Korean patients with colorectal cancer. Oncology 2010, 79:278-282.

41. Janssen EA, Soiland H, Skaland I, Gudlaugson E, Kjellevold KH, Nysted A, et al: Comparing the prognostic value of PTEN and Akt expression with the Mitotic Activity Index in adjuvant chemotherapy-treated nodenegative breast cancer patients aged $<55$ years. Cell Oncol 2007, 29:25-35.

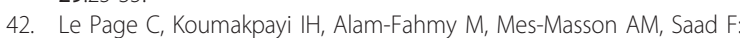
Expression and localisation of Akt-1, Akt-2 and Akt-3 correlate with clinical outcome of prostate cancer patients. Br J Cancer 2006, 94:1906-1912

43. Gazitt Y, Kolaparthi V, Moncada K, Thomas C, Freeman J: Targeted therapy of human osteosarcoma with 17AAG or rapamycin: characterization of induced apoptosis and inhibition of mTOR and Akt/MAPK/Wnt pathways. Int J Oncol 2009, 34:551-561.

44. Mayeenuddin LH, Yu Y, Kang Z, Helman LJ, Cao L: Insulin-like growth factor 1 receptor antibody induces rhabdomyosarcoma cell death via a process involving AKT and Bcl-x(L). Oncogene 2010, 29:6367-6377.

\section{doi:10.1186/1479-5876-9-200}

Cite this article as: Valkov et al:: The prognostic impact of Akt isoforms, PI3K and PTEN related to female steroid hormone receptors in soft tissue sarcomas. Journal of Translational Medicine 2011 9:200.

\section{Submit your next manuscript to BioMed Central and take full advantage of:}

- Convenient online submission

- Thorough peer review

- No space constraints or color figure charges

- Immediate publication on acceptance

- Inclusion in PubMed, CAS, Scopus and Google Scholar

- Research which is freely available for redistribution 